\title{
Non-Cash transaction behavior of people Yogyakarta City: a case from Indonesia
}

\author{
Imamudin Yuliadi ${ }^{*}$ and Yusi Ariyani \\ Department of Economics, Faculty of Economics and Business, Universitas \\ Muhammadiyah Yogyakarta, Indonesia
}

\begin{abstract}
The changes in information technology have also changed community behavior in doing transaction payments from cash to non-cash. This study aims to discover the effect of easiness, trust, life-style, and risk factors on people of Yogyakarta city interest to do a non-cash transaction. The research data were primary data obtained through interviews and questionnaires to 100 respondents in Malioboro shopping center which is the icon of Yogyakarta city, Indonesia. The data then estimated through multiple linear regression models using SPSS 16 statistical program. The result of the study empirically showed that easiness, trust, and life-style had positive and significant effects on the community's choice to have non-cash transactions. Meanwhile, risk had a negative and significant effect on the interest of people in doing non-cash transactions. In general, non-cash payment promoted the intensity and capacity of a payment transaction because the payment is easier and cheaper. This study recommends increasing community awareness about the benefits and risks of a non-cash payment transaction. Moreover, law enforcement of customer protection from the misuse of non-cash payment facilities should be enhanced.
\end{abstract}

\section{Introduction}

Indonesia's society has experienced significant changes in transaction behavior in accordance with the development of information and telecommunication technology. This study describes the non-cash payment behavior of Yogyakarta people in Indonesia. This research's novelty explains the influence of lifestyle, trust, and payment risks on non-cash payments in Indonesia, especially in Yogyakarta City. Previous research has explained people's behavior in digital transactions and their impact on the economy. $[1,3,6]$ Other similar studies have analyzed the current issue of transaction behavior using electronic money in community business activities, but not explicitly on analyzing the factors influencing non-cash transactions [1-4]. Other research also only focused on financial inclusion aspects and the role of digital technology development in influencing people's behavior in business activities but did not include trust, payment risk, and lifestyle aspects. This research on non-cash payments is interesting to study given the increasing trend of non-cash transactions from time to time. The number and value of economic transactions are emerging as the implication of

*Corresponding author: imamudin@umy.ac.id 
economic growth, which affects behavior transactions in the society, shifting from cash to non-cash transaction using electronic transactions such as ATM (Automatic Teller Machine), e-money (electronic money), credit card and debit card. The changes in transaction behavior in the society are also related to the changes of attitudes and lifestyle of rural society to urban society, which characterized as practical, easy, and efficient $[6,10]$ This condition also affected doing transactions using Payment Instrument Using Card which is considered more practical and efficient $[11,15]$. Table 1 reveals the fact about phenomena in the society in using Payment Instrument Using Card.

Table 1. Non-Cash transaction in Indonesia 2021.

\begin{tabular}{|c|c|c|c|c|}
\hline \multirow{2}{*}{ Electronic Transactions } & \multicolumn{4}{|c|}{2021} \\
\hline & March & April & Mei & June \\
\hline Non-cash Transacstion (trillion IDR) & 21.4 & 22.8 & 23.7 & 24.2 \\
\hline Debit Card Transaction (trillion IDR) & 647.2 & 659.6 & 670 & 640 \\
\hline Credit Card Transaction (million IDR) & 24.3 & 23.3 & 23.5 & 23.2 \\
\hline
\end{tabular}

The data above revealed that there was a tendency the increasing both transactions number and intensity in using Payment Instrument Using Card either in forms of credit card, debit card or ATM card. The phenomena of modern society to shop in modern markets which provide practical shopping facilities enhance the use of non-cash payment transaction instruments. The research was focused on the Malioboro region as the icon of Yogyakarta city which is one of the modern shopping centers that provides a lot of choices for society. Yogyakarta as a city of student and culture with its heterogeneous society components, from various tribes and cultures of Indonesia becomes the main choice for Indonesia people to study as well as pursue their educations. Yogyakarta becomes a national tourist attraction besides Bali because it is rich in natural, cultural, and culinary tourism attractions as well as the harmony of its society with the tradition. Malioboro tourism region becomes the icon of Yogyakarta city which is visited by many tourists either domestic or foreign. This study would reveal the non-cash transaction behavior of people of Yogyakarta that rich in culture and historical phenomena.

The study related to the non-cash transaction behavior of people of Yogyakarta was aimed to achieve the following purposes:

1. Explaining whether easiness in using Payment Instrument Using Card affected the society interest in doing non-cash transactions.

2. Explaining whether the society's trust in using Payment Instrument Using Card affected their interest in doing non-cash transactions.

3. Explaining whether the lifestyle of the people of Yogyakarta city affected their interest in doing non-cash transactions.

4. Explaining whether risk perception in using Payment Instrument Using Card affect the society in doing non-cash transactions.

\section{Literature Review}

The society's behavior in doing the non-cash transaction related to their preference in using financial institutions' services is explained using customer behavior theory, particularly attribute approach [4-7] Consumers will determine their choice of a product, either goods or service, because they consider the attribute attached to the product (Wang \& Guan, 2017). The attribute is a feature or a sign that attaches to something, which becomes the characteristics in determining identity among the other group members. Consumers purchase a good or service because there is a characteristic that attaches to the product, 
which becomes a special interest, and it can give satisfaction compared to other products. [13 - 16]. The description of consumer behavior using the attribute approach is described in Figure 1.

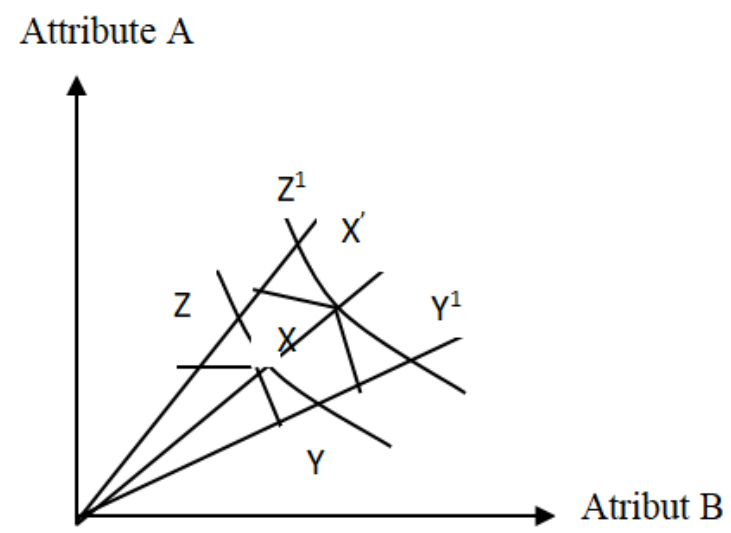

Fig. 1. Consumers' balance using attribute approach.

Source: [25]

The previous figure describes that it is assumed that there are two kinds of products, product $\mathrm{A}$ and product $\mathrm{B}$, in which each of them has a different attribute. The rational consumers try to maximize the satisfaction marked with the indifferent curve's position, which is going to the upper right. The consumer balance is marked with the intersection of the budget line with the indifferent curve. If there is a change in income level, it will change the balance point, and it will also affect the change of price rate for both product $\mathrm{A}$ and product B. Empirical studies related to economic and non-cash transactions have been conducted by previous researchers such as Harasim (2016), Wenninger and Laster (1995), who revealed a positive and significant correlation between development and technology innovation with the volume of the economic transaction conducted by the society. G. Singh (2016) in his study revealed that the stock market has a role in stimulating society economic transaction using electronic transaction. Hussin, Muhammad, Abu, and Awang (2012) explain some macro economy variables that affected society economic transaction behavior which could be seen from the development of marketable securities index in the stock market.

Some factors affect the consumers' consideration in choosing a product, such as culture, personal and social factors. The consumers will consider the cultural factor, which consists of some sub-cultures in choosing a product in which the consumers revealed their consideration in choosing a product $[33,34]$.

\section{Methodology}

This study is quantitative and investigative research to discover the Yogyakarta city community's character in doing transactions. This study was focused on the modern shopping center in Malioboro as the icon of Yogyakarta city and visited by the people of Yogyakarta and the tourists. The shopping centers that became the research objects were Malioboro Mall, Ramayana Mall, Progo Swalayan, and Ramai Mall, considering that many Yogyakarta people visit those places, and they provide non-cash payment facilities. The sampling technique used was purposive random sampling which is a sampling technique based on the consideration to obtain respondents who do the real economic transaction in 
the research field. Since the number of populations could be predicted, then the number of respondents as the research samples were determined based on the following formula:

$$
n=\frac{Z^{2} \cdot p(1-p)}{(1)^{2}}
$$

$n$ is the number of samples, $\mathrm{p}$ is the population proportion, $\mathrm{Z}$ is score $\mathrm{Z}$ with a certain degree of trust with error sampling in which p-value is around 0 until $\sim$ (incalculable). Based on that criterion, the number of samples was 100 respondents. The respondents were determined by directly conducting the study in the field to find the respondents who were going to or just finished doing the transaction in the modern market. The variables in this were people's interest as the dependent variable, while trust, lifestyle, risk, and easiness in doing non-cash transactions as independent variables. The analysis model used multiple linear regressions using the following formula:

In which:

$$
Y=a_{1} X_{1}+a_{2} X_{2}+a_{3} X_{3}+a_{4} X_{4}+e
$$

$\mathrm{Y}=$ Non-cash transaction

$\mathrm{X}_{1}=$ Trust in doing non-cash transaction

$\mathrm{X}_{2}=$ Lifestyle in doing non-cash transaction

$\mathrm{X}_{3}=$ Risk in doing non-cash transaction

$\mathrm{X}_{4}=$ Easiness in doing non-cash transaction

$e=$ error term

In the econometric model using several independent variables, the dependent variable's significance test would be carried out on the independent variable at a certain level of significance. The estimation of linear regression coefficients with variable $\mathrm{Y}$ was formulated in a matrix with an observed value of $\mathrm{n}$ from $1 \mathrm{x} \mathrm{k}$ vector of the exogenous variable $\mathrm{X}[14,23]$

$$
\underset{n x 1}{y}=\left(\begin{array}{c}
y_{t} \\
\vdots \\
y_{n}
\end{array}\right), \underset{n x 1}{X}=\left(\begin{array}{c}
X_{1}^{\prime} \\
\vdots \\
X_{n}^{v}
\end{array}\right)=\left[\begin{array}{ccc}
X_{1 t} & \cdots & X_{1 k} \\
\vdots & \ddots & \vdots \\
X_{n t} & \cdots & X_{n k}
\end{array}\right]
$$

with the following form of multiple linear functions:

$Y_{i}=\beta_{i} X_{i t}+\beta_{i} X_{i t}+\beta_{2} X_{2 t}+\beta_{3} X_{3 t}+\ldots \ldots \beta_{k} X_{i t}+u_{i} \quad i=1,2,3, \ldots, n$

$\mathrm{E}(\mathrm{u} \mid \mathrm{X})=0$

$\mathrm{E}\left(\mathrm{uu}{ }^{\prime} \mid X\right)=\sigma^{2} I_{n}$, where $I_{n}$ is an identity matrix.

$\operatorname{Rank}(\mathrm{X})=k$

The expected $\mathrm{Y}$ value from the vector $\mathrm{k} x 1$ with the exogenous variable $\mathrm{X}$ was $\mathrm{X} / \beta$, with the following formulation: $(14,23)$

$\mathrm{E}\left(\mathrm{X}^{\prime} \mathrm{u}\right)=\mathrm{E}\left[\mathrm{E}\left(\mathrm{X}^{\prime} \mathrm{u} \mid \mathrm{X}\right)\right]=\mathrm{E}\left[\mathrm{X}^{\prime} \mathrm{E}(\mathrm{u}|\mathrm{X}| \mathrm{X}]=0\right.$

$\mathrm{E}\left(\mathrm{uu}^{\prime}\right)=\mathrm{E}, \mathrm{E}\left(\mathrm{uu}^{\prime} \mid \mathrm{X}\right)=\mathrm{E}_{\mathrm{y}}$

$$
\llbracket\left[\begin{array}{ccc}
E\left(u_{i}^{2}\right. & E\left(u_{i} u_{2}\right) \ldots & E\left(U_{1} u_{n}\right) \\
\vdots & \vdots & \vdots \\
E\left(u_{n} u_{t}\right. & E\left(u_{n} u_{2}\right. & E\left(u_{n}^{2}\right.
\end{array}\right]=\left[\begin{array}{ccc}
\sigma^{2} & 0 & \ldots \\
\vdots & \vdots & \vdots \\
0 & \cdots & \sigma^{2}
\end{array}\right]
$$

The hypothesis testing for the regression coefficient is:

$\mathrm{H}_{0}: \beta_{\mathrm{j}}=0$

The t-statistic value for each independent variable could be obtained using the following formula: [23] 


$$
t=\frac{\left(\widetilde{\beta_{j}}-\beta_{j}\right) / \sqrt{\sigma^{2}}\left(X^{\prime} X\right)_{j j}^{-i}}{\sqrt{\hat{S}^{2} / \sigma^{2}}}
$$

where $\mathrm{n}-\mathrm{k}$ is the degree of freedom, with the standard error formula as follows:

$$
\begin{aligned}
\dot{S}_{j}=\sqrt{\dot{s}^{2}\left(X^{\prime} X\right)_{j j}^{-1}} & \\
& =\sqrt{\left(\frac{1}{n-k} \sum u_{i}^{2}\right)\left(X^{\prime} X\right)_{j j^{\prime}}^{-1}}
\end{aligned}
$$

The data were gained from a direct interview with the respondents through a questionnaire validated through validity and reliability tests to measure the credibility of the questionnaire instruments in gaining information from the respondents. Data analysis was conducted through descriptive statistics to discover the respondents' data characteristics. The statistical data processing was conducted using the SPSS program to discover the inference statistics, including individual statistics test (t-test), coefficient determination test $\left(\mathrm{R}^{2}\right)$, and overall model test (F test). In order to gain valid statistical results, which fulfill the criteria of the best, linear, unbiased estimator (BLUE), then classical assumption test was conducted, which included multicollinearity, heteroscedasticity, and autocorrelation test.

\section{Results and Discussion}

The data obtained from the interview with the respondents were then validated and compiled. The validity test measured how valid a question item in a questionnaire to be

\begin{tabular}{|c|c|c|c|c|}
\hline \multicolumn{5}{|c|}{ Non-Cash Transaction } \\
\hline \multirow[t]{2}{*}{ Value of KMO var. interest (Y) } & \multicolumn{4}{|c|}{ Anti-Image Correlation } \\
\hline & P1 & P2 & P3 & $\mathrm{P} 4$ \\
\hline 0.804 & $.511^{* *}$ & $.610^{* *}$ & $.576^{* *}$ & $.502^{* *}$ \\
\hline \multicolumn{5}{|c|}{ Easiness } \\
\hline \multirow[t]{2}{*}{ Value of KMO var. easiness (Y) } & \multicolumn{4}{|c|}{ Anti-Image Correlation } \\
\hline & P1 & P2 & P3 & $\mathrm{P} 4$ \\
\hline .808 & $.354^{* *}$ & $.564^{* *}$ & $.438^{* *}$ & $.424^{* *}$ \\
\hline \multicolumn{5}{|c|}{ Risk } \\
\hline \multirow[t]{2}{*}{ Value of KMO var. Risk (Y) } & \multicolumn{4}{|c|}{ Anti-Image Correlation } \\
\hline & P1 & P2 & P3 & P4 \\
\hline .819 & .473 & .508 & .363 & .418 \\
\hline \multicolumn{5}{|c|}{ Lifestyle } \\
\hline \multirow[t]{2}{*}{ Value of KMO var. Lifestyle (Y) } & \multicolumn{4}{|c|}{ Anti-Image Correlation } \\
\hline & P1 & $\mathrm{P} 2$ & P3 & $\mathrm{P} 4$ \\
\hline .715 & .354 & .564 & .438 & .424 \\
\hline \multicolumn{5}{|c|}{ Trust } \\
\hline \multirow[t]{2}{*}{ Value of KMO var. Trust (Y) } & \multicolumn{4}{|c|}{ Anti-Image Correlation } \\
\hline & P1 & $\mathrm{P} 2$ & P3 & P4 \\
\hline .801 & $.310^{* *}$ & $.277^{* *}$ & $.432^{* *}$ & $.430^{* *}$ \\
\hline
\end{tabular}
studied was. The results of the validity test from research variables were shown in Table 2 .

Table 2. KMO table and anti image correlation. 
Kaiser-Meyer-Oikin (KMO) result test (refers to Table 2) for interest variable was 0.804 $>0.05,0.808>0.05$ for variable of easiness, $0.819>0.05$ for risk variable, $0.715>0.05$ for lifestyle variable, $0.801>0.05$ for trust variable, it means that those variables were valid to be used for the research. Meanwhile, anti-image correlation showed that the value of question item $1(\mathrm{P} 1)$ was 0.549 , question item 2 (P2) was 0.538 , question item $3(\mathrm{P} 3)$ was 0.637 , item question 4 (P4) was 0.805 , which meant that all the question items' value $>$ 0.05 , it showed that those four-question items fulfilled the criteria in measuring construct on interest research variable. The result of anti-image correlation showed that the value of question item $1(\mathrm{P} 1)$ was 0.354 , question item $2(\mathrm{P} 2)$ was 0.564 , question item $3(\mathrm{P} 3)$ was 0.438 , and question item $4(\mathrm{P} 4)$ was 0.424 , it indicated that all of the question item' value was $>0.05$ which described that those four items fulfilled the criteria on measuring the construct on lifestyle research variable. The result of anti-image correlation showed that the value of question item $1(\mathrm{P} 1)$ was 0.473 , question item 2 (P2) was 0.508 , question item 3 (P3) was 0.363 , question item $4(\mathrm{P} 4)$ was 0.418 , which meant that all the question items' values were $>0.05$, it indicated that those four items fulfilled the criteria in measuring the construct of trust research variable. [30, 31].

The validity of the variable in this study could be seen from the value of $r$ Pearson correlation and the significant model as shown in Table 3.

Table 3. R Pearson correlation value and significant model.

\begin{tabular}{|c|c|c|c|c|}
\hline \multicolumn{5}{|c|}{ Non-Cash Transaction } \\
\hline Item & r Pearson correlation & r table & significance & Conclusion \\
\hline P1 & $.549^{* *}$ & 0.3610 & 0.000 & Valid \\
\hline P2 & $.538^{* *}$ & 0.3610 & 0.000 & Valid \\
\hline P3 & $.637^{* *}$ & 0.3610 & 0.000 & Valid \\
\hline P4 & $.805^{* *}$ & 0.3610 & 0.000 & Valid \\
\hline \multicolumn{5}{|c|}{ Trust } \\
\hline Item & r Pearson correlation & r table & significance & Conclusion \\
\hline P1 & $.801^{* *}$ & 0.3610 & 0.000 & Valid \\
\hline P2 & $.650^{* *}$ & 0.3610 & 0.000 & Valid \\
\hline P3 & $.628^{* *}$ & 0.3610 & 0.000 & Valid \\
\hline P4 & $.805^{* *}$ & 0.3610 & 0.000 & Valid \\
\hline \multicolumn{5}{|c|}{ Easiness } \\
\hline Item & r Pearson correlation & r table & significance & Conclusion \\
\hline P1 & $.563^{* *}$ & 0.3610 & 0.000 & Valid \\
\hline P2 & $.553^{* *}$ & 0.3610 & 0.000 & Valid \\
\hline P3 & $.625^{* *}$ & 0.3610 & 0.000 & Valid \\
\hline P4 & $.798^{* *}$ & 0.3610 & 0.000 & Valid \\
\hline \multicolumn{5}{|c|}{ Lifestyle } \\
\hline Item & r Pearson correlation & r table & significance & Conclusion \\
\hline P1 & $.606^{* *}$ & 0.3610 & 0.000 & Valid \\
\hline P2 & $.663^{* *}$ & 0.3610 & 0.000 & Valid \\
\hline P3 & $.684^{* *}$ & 0.3610 & 0.000 & Valid \\
\hline P4 & $.672^{* *}$ & 0.3610 & 0.000 & Valid \\
\hline \multicolumn{5}{|c|}{ Risk } \\
\hline Item & r Pearson correlation & r table & significance & Conclusion \\
\hline P1 & $.532^{* *}$ & 0.3610 & 0.000 & Valid \\
\hline P2 & $.667^{* *}$ & 0.3610 & 0.000 & Valid \\
\hline P3 & $.669^{* *}$ & 0.3610 & 0.000 & Valid \\
\hline \multicolumn{5}{|c|}{} \\
\hline
\end{tabular}




\begin{tabular}{|l|l|l|l|l|}
\hline P4 & $.839^{* *}$ & 0.3610 & 0.000 & Valid \\
\hline
\end{tabular}

Based on the result of the validity test (see Table 3 ) elaborated previously, it showed that for question items no $1-4$, the value of $r$ Pearson correlation was higher than the value of $r$ table, which was 0.3610 , or the significance value was smaller than $0.005(5 \%)$ it means that each question on the variable of interest, trust, risk, easiness, lifestyle, was valid and they could measure those research variables. [20-22]

Another research test instrument is the reliability test to discover whether the items of research questions are consistent from time to time. A variable is considered reliable when Cronbach Alpha's value is higher than 0.6, which meant that that variable is consistent from time to time. The analysis result of reliability on the variable of interest, lifestyle, risk, trust, and easiness is described in Table 4.

Table 4. Cronbach alpha value.

\begin{tabular}{|c|c|c|c|c|}
\hline \multicolumn{5}{|c|}{ Non-Cash Transaction } \\
\hline \multirow[t]{2}{*}{ Chronbach's Alpha } & \multicolumn{4}{|c|}{ Chronbach's Alpha if item deleted } \\
\hline & P1 & P2 & P3 & $\mathrm{P} 4$ \\
\hline 0.826 & $.779^{* *}$ & $.796^{* *}$ & $.784^{* *}$ & $.764^{* *}$ \\
\hline \multicolumn{5}{|c|}{ Easiness } \\
\hline \multirow[t]{2}{*}{ Chronbach's Alpha } & \multicolumn{4}{|c|}{ Chronbach's Alpha if item deleted } \\
\hline & P1 & P2 & P3 & P4 \\
\hline .829 & $.753^{* *}$ & $.843^{* *}$ & $.743^{* *}$ & $.797^{* * 3}$ \\
\hline \multicolumn{5}{|c|}{ Risk } \\
\hline \multirow[t]{2}{*}{ Chronbach's Alpha } & \multicolumn{4}{|c|}{ Chronbach's Alpha if item deleted } \\
\hline & P1 & P2 & P3 & P4 \\
\hline .877 & $.851 * *$ & $.863 * *$ & .817 & .834 \\
\hline \multicolumn{5}{|c|}{ Lifestyle } \\
\hline \multirow[t]{2}{*}{ Chronbach's Alpha } & \multicolumn{4}{|c|}{ Chronbach's Alpha if item deleted } \\
\hline & P1 & $\mathrm{P} 2$ & P3 & P4 \\
\hline .880 & .884 & .852 & .838 & .810 \\
\hline \multicolumn{5}{|c|}{ Trust } \\
\hline \multirow[t]{2}{*}{ Chronbach’s Alpha } & \multicolumn{4}{|c|}{ Chronbach's Alpha if item deleted } \\
\hline & P1 & P2 & P3 & $\mathrm{P} 4$ \\
\hline .899 & $.864^{* *}$ & $.852^{* *}$ & $.880^{* *}$ & $.881^{* *}$ \\
\hline
\end{tabular}

The result of the reliability test (see Table 4) elaborated in the table above revealed that Chronbach's Alpha values on all variables being studied: interest, risk, easiness, trust, lifestyle were greater than 0.6 it means that generally, all questions in each variable on that research was reliable. The greatest value was on the trust variable of 0.899 , and the smallest was 0.826 on the interest variable. It was also shown on the value of Chronbach's Alpha on each question for P1, P2, P3, and P4, which indicated a greater value than 0.6 . The greatest value was on the easiness variable on question 1 (P1) for 0.884 , and the smallest one was on the lifestyle variable on the third question (P3) for 0.743 . The result of the measurement implied that each question on all variables of interest, risk, easiness, trust, and lifestyle in this study was reliable to use as a research variable [27, 29].

The economic transaction behavior of people of Yogyakarta city is in accordance with the characteristic of Yogyakarta as an education city as well as cultural city which is occupied by people from all over the places in Indonesia with their kinds of social, economy, customs, cultures, education, religions, and ethnics backgrounds. This situation affects their shopping behavior either related to the kinds of goods purchased, the value, place, time, and ways of transaction. The non-cash transaction behavior of Yogyakarta 
people tends to develop in accordance with the changes of needs and the need for transaction facilities that give easy and cheap service. The result of the classical assumption test on the research model and empirical analysis on the non-cash transaction behavior of Yogyakarta people is described in Table 5.

Table 5. Regression analysis and classical assumption.

\begin{tabular}{|l|c|c|c|}
\hline \multicolumn{1}{|c|}{ Variable } & Coefficient & Prob. & Note \\
\hline C & 2.248 & 0.188 & - \\
\hline Trust & 0.345 & 0.000 & Significant \\
\hline Easiness & 0.374 & 0.000 & Significant \\
\hline Lifestyle & 0.232 & 0.001 & Significant \\
\hline Risk & -0.128 & 0.024 & Significant \\
\hline Observer R squared & 0.029 & & No heteroscedasticity \\
\hline Durbin-Watson Statistics & 1.634 & & No autocorrelation \\
\hline R-squared & 0.565 & \multicolumn{3}{|l}{} \\
\hline Adjusted R-squared & 0.547 & 30.894 \\
\hline F statistic & 0.000000 & \\
\hline Prob. (F-statistic) &
\end{tabular}

The empirical result (see Table 5) elaborated above showed that based on the classical assumption test, the research model about non-cash transactions of Yogyakarta people was free from the problem of classical assumption, namely autocorrelation and heteroscedasticity. While the regression result on all independent variables (trust, easiness, lifestyle, and risk) in this study showed that the value of $\mathrm{t}$-count was higher than the t-table on $\alpha=5 \%$; it means each independent variable affected the interest of the people of Yogyakarta in doing non-cash transaction. The smallest coefficient regression was on the lifestyle aspect for 0.232 , which meant when the value of lifestyle increased as much as 1 , it would increase non-cash transaction use by 0.232 . Society conducts economic transactions is not merely to fulfill their basic needs but also as part of their lifestyle, including the use of transaction instruments, either cash or non-cash. There was a tendency that when a person's economic level was higher, then the use of non-cash payment instruments such as ATM, credit card, debit card, check, etc., would increase. This study's results are unique compared to research in Nigeria, which only explained access to transactions and the use of banking services in supporting community economic transactions without including aspects of lifestyle and trust in public financial transactions $[5,8]$.

On the other hand, a society with a low economic level would tend to use cash payment because the number and the frequency of transactions were relatively small. The more noncash payment instruments that someone possesses, the higher his/her social status will be because it shows that he/she has many savings in the bank. Research on aspects of a person's status in society related to non-cash transaction behavior is different from Mishra $\&$ Nathan's research results on social openness aspects and its effects on the implications of multidimensional development and measurement of the quality of human resources [3-6] The people of Yogyakarta's interest to have non-cash transactions as part of their lifestyle was relatively the smallest because of the character of the people of Yogyakarta in general, whose life is relatively simple and do not want to show off in shopping. Therefore, the people of Yogyakarta tend to be conservative in terms of choosing the transaction model, and it is not crucial in the choice of shopping lifestyle. Non-cash and semi-non-cash were also conducted by Yogyakarta people, for instance, in reserving a plane ticket, train ticket, hotel, vehicle rental, etc. It shows that, in general, there is a tendency for the community to get used to doing electronic transactions. Other similar studies have been conducted in Peru and China, which examined the financial openness factor and its implications for the 
behavior of public financial transactions but did not explicitly include lifestyle variables [18-21].

The coefficient regression value on the easiness variable was 0.374 , which meant that when there was an incensement on the easiness aspect as many as 1 point, it would increase the interest to have a non-cash transaction by 0.374 . The coefficient regression value on this easiness variable was the highest compared to the other research variables. This condition became the main aspect for the community to have non-cash transactions because of the facilities that ease them shopping. Using electronic cards such as ATM, credit card, debit card, e-money, etc., make them easier to do the transaction, especially in modern markets which provide non-cash transactions. They only need to bring that electronic payment to do the transaction no matter how much they want to, as long as they have enough savings. It will be different when they have to make a cash transaction and carry money from home to the transaction and when they have to count the money one by one to arrive at a specific sum. This condition will not happen in a non-cash transaction in which the amount of payment will be exact, and it also reduces the risk of using counterfeit money. Another problem that may arise in cash transactions is that when they quite often get defective money, it reduces its acceptance in the transaction. Similar research has been carried out in India and Nigeria regarding the phenomenon of E-Banking and its effect on the behavior of public financial transactions but did not explicitly include the ease of transaction variables [25-31].

The coefficient regression value on the risk variable was -0.128 it means when the risk increased 1 point, it will reduce the community interest to have electronics transaction for 0.128 . There is an adagio that there will be a risk that has to be faced in each easiness, and it happened to the community's interest in doing the non-cash transaction in the Yogyakarta community. The possible risk that may occur on the non-cash transaction is when the payment instrument, either in the forms of the card, PIN, username, etc., is broken, lost, or known by other irresponsible people. Those possible risks became the consideration for the people of Yogyakarta to choose non-cash transactions. ATM cards, credit cards, e-money, checks, etc., besides providing many easiness facilities, also have some risks. There were many cases in which the savings were decreasing significantly because unauthorized people broke the account numbers. There were also some cases where the ATM card was swallowed by the machine when withdrawing money, making economic transactions fail. Another case was ATM card was folded, got stains, which make it unable to withdraw some money from the ATM. Those cases also happened on non-cash payment in the form of electronic money. However, another reason the use of those non-cash payment instruments also reduces some other risks. Research on risk in non-cash transactions has been mainly carried out in developed countries and is still rare in developing countries, for example, research on the risk of non-cash transactions in Canada as a developed country, with a reasonably good financial system; however, the study did not include lifestyle and trust variables [20-24].

The coefficient regression for the trust variable was 0.345 , meaning that if the trust of the people of Yogyakarta for non-cash transactions increased for $i$ point, then their interest to have non-cash transactions increased by 0.345 points. This empirical finding was in accordance with the theoretical review and other empirical findings that the community decided in doing non-cash transaction because they believe that those facilities were able to be used for the real transaction. There are some possibilities of their worries such as broken machine, and the supermarket does not provide non-cash payment facilities, there is a blackout so the machine will not work, electronics card forgery, etc. Nevertheless, in accordance with the advances of technology, those worries are eliminated and avoided so that non-cash payment facilities become the choice for the people of Yogyakarta. Another study that has also included the trust variable but more on its effect on financial 
transactions, in general, is research conducted by Japelli. Q \& Padula M on financial literacy and decisions on saving [11-14].

There are some positive effects of the increased electronic payment or non-cash payment such as stimulating economic transactions to be faster and efficient, avoiding the possibility of receiving counterfeit or defective money, reducing the burden of the state budget in printing cartel money (paper money and coins) and enhancing the social awareness and knowledge about the function of money and financial institution [17].

\section{Conclusions}

Yogyakarta community, which is heterogeneous with its kinds of condition and social, economic, cultural, religious, ethnic, and educational backgrounds, tends to increasingly use non-cash payments such as ATM cards, credit cards, debit cards, and electronic money (e-money). The empirical study result showed that using electronics transaction instruments or non-cash payment was affected significantly by the trust, easiness, lifestyle, and risk variables. The positive and significant effects were on trust, easiness, and lifestyle variables, which meant that the increased level of trust, easiness, and lifestyle choice increased the interest to have non-cash transactions. Meanwhile, the risk variable showed a negative and significant effect on the interest of the people of Yogyakarta to have a noncash transaction. The enhancement of the non-cash payment instrument will give a positive impact on the economic development of the Yogyakarta community, especially to increase the economics transaction efficiency, reduce the risk of counterfeit and defective money circulation, increase the community awareness about money literacy that us the knowledge about money and financial institution [4-7].

Author Contributions: Conceptualization, methodology, software, validation, and formal analysis, I.Y.; investigation, resources, data curation, writing - original draft preparation, writing-review and editing, I.Y and Y.A; visualization, supervision, and project administration, Y.A.

Conflicts of Interest: The authors declare no conflict of interest.

\section{References}

1. Alfares, Cliford. The Problem Regarding Fake Currency in India, Business Today, Vol. 18, issues 5, p. 24-39 (2019).

2. Anil Kumar Punna, Mahesh Kumar Punna, Money Transactions trough Mobile (Anywhere, Anytime, Anybode, Any Needs). Asian Journal of Banking and Finance, Vol. 7, No. 7, p. 233-239 (2017).

3. Arora R.U. Access to Finance an Empirical Analysis, European Journal of Development Research, 26, p. 798-814 (2014).

4. Ardiansah, M., Chariri, A., Rahardja, S., \& Udin, U. The effect of electronic payments security on e-commerce consumer perception: An extended model of technology acceptance. Management Science Letters, 10(7), 1473-1480 (2020).

5. Auta, Elisha Menson. E-Banking in Developing Economy Empirical Evidence from Nigeria, Journal of Applied Quantitative Methods, vol. 5, no. 2 (2010).

6. Camara N, Pena X \& Tuesta D. Factors that Matter for Financial Inclusions Evidence from Peru, The International Journal of Finance, (forth coming) (2014). 
7. Chakravarthy. S.R \& Pal. R. Financial Inclusions in India an Axiomatic Applied, Journal of Policy Modelling, 35, p. 813-837 (2013).

8. Chang, H. H., \& Chen, S. W. Consumer perception of interface quality, security, and loyalty in electronic commerce. Information \& Management, 46(7), 411-417 (2009).

9. C. Thilagavathy, \& Dr. S. Naga Santhi. Impact and Importance of Cashless Transaction in India, International Journal of Recent Research and Applied Studies, Vol. 4, issues 10(1), p. 1-4 (2017).

10. Demirguc. Kant A, Klapperl, Singer D, Oupheusden PV. Measuring Financial Inclusion and The Fintech Revolution, The Global Findex Data Base (2014).

11. Dostov Victor, Shust Pavel, Khorkova Anna. New Trend in Financial Inclusion Policies Role of Digital Technologies and Digital Inclusion Advances in Economies, Business and Management Research, vol. 104 (2018).

12. Fungacova $Z \&$ Weill L. Understanding Financial Inclusion in China, China Economic Review, 34, p. 196-206 (2015).

13. Fung Ben, Miguel Molico \& Gerald Stuber. Electronic Money and Payments Recent Development and Issues, Bank of Canada, Discussions Paper-2 (2014).

14. Gujarati, Damodar, 2004, Basic Econometrics, McGraw-Hill

15. Harasim, J. Europe: the shift from cash to non-cash transactions Transforming Payment Systems in Europe (pp. 28-69): Springer (2016).

16. Hussin, M. Y. M., Muhammad, F., Abu, M. F., \& Awang, S. A. Macroeconomic variables and Malaysian Islamic stock market: a time series analysis. Journal of business studies quarterly, 3(4), 1-13 (2012).

17. Japelli. T \& Padula M. Investment in Financial Literacy and Saving Decision, Journal of Banking and Finance, 37, p. 2779-2792 (2013).

18. Karlan D, Kendall J, Mann R, Pande. R Suri. T, Sinman J. Research and Impact of Digital Financial Services, NBER, Working Paper 22633 (2016).

19. Kim D, Yu. J \& Hassan M.K. Financial Inclusion and Economic Growth in OIC Countries, Research in International Business and Finance, 43, p. 1-14 (2018).

20. Kim, C., Tao, W., Shin, N., \& Kim, K.-S. (2010). An empirical study of customers' perceptions of security and trust in e-payment systems. Electronic Commerce Research and Applications, 9(1), 84-95 (2010).

21. Klugman J, Rodriguez F.R \& Choi H.J. The Human Development Index 2010 New Controversies Old Critiques, Journal of Economic Inequality, 9, p. 249-288 (2011).

22. Lenka S.K, Bairwa A.K. Does Financial Inclusions Affect Monetary Policy in SAARC Countries ?, COCEAC Economic and Finance, 4(1), 1127011 (2016).

23. Michael Intriligator, Ronald Bodkin, Cheng Hsiao. Econometric Models, Techniques and Applications, Prentice Hall International Editions (1996).

24. Mishra S, Nathan H.S.K. Meausering Human Development Index The Old The New and The Elegant Implications for Multidimensional Development and Social Inclusiveness, LSE Asia Research Centre Working Paper 63 (2014).

25. Semasinge, W.M. Attribute Theory of Consumer Behavior, Journal of Political Economy, 74, p. 132-157 (1996).

26. Singh, G. The impact of macroeconomic fundamentals on stock prices revised: A study of Indian stock market. Journal of International Economics, 7(1), 76-91 (2016).

27. Singh, S., \& Rana, R. Study of consumer perception of digital payment mode. Journal of Internet Banking and Commerce, 22(3), 1-14 (2017). 
28. Srinivas. N. An Analysis of The Defaults in Credit Card Payments, Southern Economics, p. 19-21 (2006).

29. Uchenna Efobi, Ibukun Beecroft, Evans Osa Buohien. Access to and Use of Bank Services in Nigeria Microeconometric Evidence, Review of Development Finance, 52 (2014).

30. Wang X \& Guan J. Financial Inclusion Measurement Spatial Effect and Influencing Factors, Applied Economics, 49(18), p. 1751-1762 (2017).

31. Wenninger, J., \& Laster, D. The electronic purse. Current Issues in Economics and Finance, 1(1), 1-5. (1995).

32. Yuliadi, Imamudin. An Analysis of Money Supply in Indonesia Vector autoregressive (VAR) Approach, Journal of Asian Finance, Economics and Business, 7(7), p. 241-249 (2020).

33. Susanawati, H. Akhmadi, M. Fauzan, and Z. Rozaki, Supply chain efficiency of red chili based on the performance measurement system in Yogyakarta, Indonesia. Open Agric. 6, 202 (2021).

34. Z. Rozaki, Susanawati, D. Rina Kamardiani, and A. Kartika Huda, Consumer Preferences for Fresh and Frozen Local Beef in Sleman Regency, Indonesia. in E3S Web Conf. (2021). 